\title{
Doctoral Supervision in the Light of the Three Types of Support Promoted in Self-Determination Theory
}

\author{
Christelle Devos \\ Université catholique de Louvain \\ Louvain-la-Neuve, Belgium \\ christelle.devos@uclouvain.be \\ Gentiane Boudrenghien \\ Université catholique de Louvain \\ Louvain-la-Neuve, Belgium \\ gentiane.boudrenghien@uclouvain.be
Mariane Frenay and Benoit Galand Université catholique de Louvain
Louvain-la-Neuve, Belgium \\ mariane.frenay@uclouvain.be \\ benoit.galand@uclouvain.be
}

\author{
Nicolas Van der Linden \\ Université Libre de Bruxelles \\ Bruxelles, Belgium \\ nivdlind@ulb.ac.be
}

Assaad Azzi

Université Libre de Bruxelles Bruxelles, Belgium

aazzi@ulb.ac.be

Olivier Klein

Université Libre de Bruxelles

Bruxelles, Belgium

oklein@ulb.ac.be

\begin{abstract}
The purpose of the present study was twofold. First, we used the three types of support depicted in Self-Determination Theory (SDT) (structure, involvement and autonomy support) to examine supervision practices in the doctoral context. Conversely, we used this material to discuss the theory and suggest new developments to it.

To this end, we conducted semi-structured interviews with 21 former $\mathrm{PhD}$ students $(8$ completers and 13 non-completers). The data were analyzed using deductive content analysis. The first aim led us to illustrate how supervisors offer structure, involvement, and autonomy support to the doctoral students, and to support the relevance of this theoretical framework in this particular

Material published as part of this publication, either on-line or in print, is copyrighted by the Informing Science Institute. Permission to make digital or paper copy of part or all of these works for personal or classroom use is granted without fee provided that the copies are not made or distributed for profit or commercial advantage AND that copies 1) bear this notice in full and 2) give the full citation on the first page. It is permissible to abstract these works so long as credit is given. To copy in all other cases or to republish or to post on a server or to redistribute to lists requires specific permission and payment of a fee. Contact Publisher@InformingScience.org to request redistribution permission. context. The second aim led us to provide three avenues for reflection on SDT.

First, a set of practices belongs both to structure and involvement and are therefore at risk of being overlooked in research. Second, there is a thin line between structure and control (and between autonomy support and chaos) and intentions to offer the first may easily
\end{abstract}


turn into providing the second in practice. Finally, we developed the hypothesis that a necessary condition for supervisors to be able to offer positive support to their doctoral students is to consider them as trustworthy.

Keywords: Doctoral students, $\mathrm{PhD}$, supervision, supervisor, self-determination theory, qualitative.

\section{Introduction}

According to Barnes and Austin (2009, p. 297), "the doctoral advisor is said to be one of the most important persons - if not the single most critical person - with whom doctoral students will develop a relationship during their doctoral degree program (Baird, 1995)". A large body of research focuses on the relationship between PhD students and their supervisors and on the influence that this relationship may have on their doctoral journey (McAlpine \& McKinnon, 2013). According to Jones' (2013) literature review, 15\% of the research in doctoral studies focuses on the student-supervisor relationship.

\section{Supervisor Support}

Studies investigating doctoral advisors' supervision practices take various perspectives and focus on different aspects of this issue; they advise supervisors with good practices, identify supervision styles and related questionnaires, analyze the influence of supervisory styles on students' outcomes, or, more recently, investigate students' expectations regarding their ideal supervisor. We describe these lines of research below.

First, several authors have identified different supervisory management styles (e.g. Deuchar, 2008; Franke \& Arvidsson, 2011; Gatfield, 2005; Grant, Hackney, \& Edgar, 2014; Lee, 2008; Vilkinas, 2008) and developed questionnaires in order to assess the quality of supervision in various dimensions (e.g. Bell-Ellison \& Dedrick, 2008; Berk, Berg, Mortimer, Walton-Moss, \& Yeo, 2005; Mainhard, van der Rijst, Tartwijk, \& Wubbels, 2009; Rose, 2003; Schlosser \& Kahn, 2007). Gurr (2001) distinguished between "hands-on" and "hands-off" supervision styles. Gatfield (2005) identified the pastoral, contractual, laissez-faire and directorial supervision styles. Franke and Arvidsson (2011) found two main supervision structures, which they called the research practice-oriented and research relation-oriented styles; these arose when $\mathrm{PhD}$ students were working on research similar to or different from that of their supervisor. Rose's (2003) "Ideal mentor scale" considers three dimensions: integrity, guidance and relationship.

Second, another line of research has investigated the influence of the advisors' support style - or of the student-advisor relationship - on various students' outcomes (Hollingsworth \& Fassinger, 2002; Jairam \& Kahl, 2012; Martinsuo \& Turkulainen, 2011; Paglis, Green, \& Bauer, 2006; Wao $\&$ Onwuegbuzie, 2011). In a longitudinal study over five years, Paglis et al. (2006) found that the quality of advisors' supervision had an impact on $\mathrm{PhD}$ students' research productivity, career commitment, and self-efficacy. In a quantitative study, Martinuso and Turkulainen (2011) found that supervisor and time commitment considered together had a positive impact on research progress. Zhao, Golde and McCormick (2007) found that advisor behaviors (e.g. academic advising, interest and support, career coaching) were related to doctoral students' satisfaction. Finally, in a qualitative study, Jairam and Kahl (2012) underlined the role of advisors' professional support, that is, feedback, advice and problem-focused assistance, for degree completion.

Third, more recently and from the students' perspective, several studies have investigated students' expectations with regard to their supervision and the characteristics that they value in a supervisor (Barnes, Williams, \& Archer, 2010; Bell-Ellison \& Dedrick, 2008; Lee, 2008; Pole \& Sprokkereef, 1997; Zhao et al., 2007). Barnes et al. (2010, p. 34) concluded, on the basis of openended survey responses, that "students spoke most positively about advisors who were accessible 
and helpful as well as socializing and caring. Conversely, they identified being inaccessible, unhelpful, and uninterested as negative attributes of advisors". Bell-Ellison and Dedrick (2008) found that the ideal mentor's most valued characteristics were to believe in the doctoral students, to value them as persons, to help them to maintain a clear focus on their research objective, and to treat them as adults who have the right to be involved in the decisions that affect them.

\section{Limitations of Previous Work}

A significant number of studies have therefore highlighted those supervisory practices likely to play a positive role in their emotions, motivation, engagement and persistence. However, existing studies have often relied on an inductive approach or on previous empirical work. Few studies have based their qualitative analysis or questionnaires on a sound theoretical framework (e.g. Lee, 2008; Mainhard et al., 2009). As stated by Lee (2008, p. 267), "literature about doctoral supervision has concentrated on describing the ever lengthening lists of functions that must be carried out. This functional approach is necessary, but there has been little exploration of a different paradigm, a conceptual approach towards research supervision". This line of work therefore lacks a strong theoretical grounding, which would offer new perspectives for understanding these processes. First, using a sound theoretical framework for the analysis makes it possible to consider supervisory practices in the light of validated categories of analysis and to interpret the results in the light of this framework. Second, it allows comparison and integration of the results with those obtained in other contexts and studies using the same framework. Third, it offers a deeper understanding of the psychological processes underlying the relationship between supervisor support and students' outcomes. Fourth, and conversely, the new data are likely to question and contribute to the development of the theoretical framework used in the analysis.

A theoretical framework that is particularly relevant for investigating $\mathrm{PhD}$ students' supervisory experiences is Basic Need Theory (BNT), which is part of Self-Determination Theory (SDT) (Deci \& Ryan, 2000). We present this framework below and then develop its relevance for studying doctoral advisors' supervisory styles.

\section{Self-Determination Theory}

SDT is an extensive theory of motivation. It encompasses different aspects and processes. Vansteenkiste, Niemiec and Soenens (2010) present these aspects as "five mini-theories": the cognitive evaluation theory (focusing on the factors that undermine or support intrinsic motivation), the organismic integration theory (suggesting that extrinsic motivation can be more or less internalized and that six types of motivation can be identified and placed on a continuum ranging from controlled motivation to autonomous motivation), the causality orientation theory (considering the different types of motivation at the dispositional level), the goal content theory (examining goal content) and the basic needs theory (stating that individuals experience three basic needs, which may be supported or thwarted by the environment), which is of particular interest for the present study.

In the present study, we focus on one aspect of BNT: the three dimensions of the social environment that support individuals' basic needs and therefore lead to positive motivational, emotional and behavioral outcomes. This theoretical framework is developed in two sections below. First, we present a brief overview of SDT. Second, we develop in more detail the three types of support described in the theory.

\section{SDT: Overview}

SDT states that individuals may display different types of motivations - or "regulations"- when engaging in activities and pursuing their goals. These motivations can be presented on a continu- 
um ranging from controlled (e.g. external regulation) to autonomous motivations (e.g. intrinsic regulation) (Deci \& Ryan, 2000; Vansteenkiste et al., 2010). According to the authors, autonomous motivations lead to more positive outcomes (e.g. well-being, learning, persistence and performance) than controlled motivations. Upstream, autonomous and internalized motivations are "facilitated by conditions that conduce toward basic need satisfaction" (Deci \& Ryan, 2000, p. 228).

These three basic needs are innate, universal, and essential for ongoing psychological growth, integrity and wellbeing (Deci \& Ryan, 2000). First, the need for competence refers to experiencing mastery. This is the propensity "to have an effect on the environment as well as to attain valued outcomes within it" (Deci \& Ryan, 2000, p. 231). Second, the need for affiliation or relatedness refers to the desire to feel connected to others, to love and care, and to be loved and cared for. More precisely, it refers to the tendency "to seek attachments and experience feelings of security, belongingness, and intimacy with others" (Deci \& Ryan, 2000, p. 252). Third, the need for autonomy refers to volition; that is, to "the organismic desire to self-organize experience and behavior and to have activity concordant with one's integrated sense of self" (Deci \& Ryan, 2000, p. 231). According to the authors, autonomy is often incorrectly equated with the ideas of internal locus of control, independence, or individualism. Autonomy in SDT, however, concerns "the experience of integration and freedom, and it is an essential aspect of healthy human functioning" (p. 231). It may be related to the construct of individual agency used in doctoral research (McAlpine \& Mitra, 2015).

These needs may be supported or thwarted by the social working environment. Deci and Ryan (2000, p. 229) "expect to observe optimal development and well-being under facilitating conditions that support need satisfaction, and to observe degradation or ill-being under conditions that thwart basic need satisfaction". More specifically, the authors have identified three dimensions of the social environment likely to support (or thwart) need satisfaction: autonomy support (rather than control or coercion), structure (rather than chaos) and interpersonal support/involvement (rather than cold, neglect or rejection) (Stroet, Opdenakker, \& Minnaert, 2013; Vansteenkiste et al., 2010). A large body of research has focused on these three types of support; in particular, to study their antecedents and consequences (see Stroet et al., 2013 for a review; Gillet, Gagné, Sauvagère, \& Fouquereau, 2013). These three dimensions are described in details below.

\section{SDT: Types of support}

Autonomy-supportive style versus control or coercion. Autonomy support refers to the amount of freedom one is given to determine one's own behavior (Skinner \& Belmont, 1993). More specifically, autonomy-supportive socializers promote students' volition by adopting three categories of behaviors (Jang, Reeve, \& Deci, 2010). First, they nurture inner motivational resources. That is, they create opportunities for students to take the initiative, provide choices, offer latitude in learning activities, display patience in allowing time for self-paced learning, and facilitate the congruence between the proposed activities and the students' autonomous sources of motivation (Jang et al., 2010; Reeve, 2009; Skinner \& Belmont, 1993). Second, they rely on non-controlling informational language. That is, they offer rationales for the requested activities and communicate through messages that are informative, flexible and rich in competence-related information (Jang et al., 2010; Vansteenkiste, et al., 2010). Third, they try to understand and acknowledge students' perspectives and feelings. That is, they are curious about and value them, and accept the expression of negative affects. In sum, they support motivational development and the capacity for autonomous self-regulation (Reeve, 2009).

Controlling socializers, on the other hand, "pressure students to think, feel, or behave in a specific way" (Reeve, 2009; Vansteenkiste et al., 2010). Reeve (2009, p. 161) stresses that the starting point for a controlling motivation style is "the prioritization of the teacher's perspective to the 
point that it overruns the students' perspective". Asking a student to behave, feel or think in a certain way becomes controlling only if the teacher neglects the student's perspective (not asking why the student is doing what $\mathrm{s} / \mathrm{he}$ is doing), becomes intrusive, or applies pressure (i.e. forceful language, guilt-inducing criticisms) to think, feel or behave in a specific way.

In addition, control can be direct (or external) or indirect (or internal) (Reeve, 2009). Direct control involves a teacher's "explicit and overt attempts to motivate students by creating external compulsions to act, such as through the imposition of deadlines, verbal commands, or environmental incentives" (p.161). Indirect control involves a teacher's "subtle or covert attempts to motivate students by creating internal compulsions to act" (p. 161), such as through feelings of guilt, shame, and anxiety, by threatening to withdraw attention or approval, or by cultivating perfectionist standards.

Structure versus chaos. Structure refers to "the amount and clarity of information that teachers provide to students about expectations and ways of effectively achieving desired educational outcomes (Skinner \& Belmont, 1993; Skinner et al., 1998)" (Jang et al., 2010, p. 589).

More specifically, these authors identify three categories of behaviors adopted by structured socializers. First, they offer clear, understandable, explicit, and detailed directions, that is, "they establish clear expectations with respect to students' future behavior and prescribe ways for students to manage their moment-to-moment activity during a forthcoming learning activity" ( $p$. 590). Second, they offer a program of action to guide students' ongoing activity, that is, they offer strong guidance, and they provide students with "the leadership and the scaffolding needed for students to instigate and maintain effort toward achieving their plans, goals, and learning objectives" (p. 590). Third, they offer constructive feedback on how students can gain control over valued outcomes, that is, "they help students diagnose and build on their skills and sense of competence" (p. 590). These behaviors are likely to "help students to develop a sense of perceived control over school outcomes, that is, to develop perceived competence, an internal locus of control, mastery motivation rather than helplessness, self-efficacy, and an optimistic attributional style (Skinner, 1995; Skinner et al., 2008)" (Jang et al., 2010, p. 590).

The opposite of structure is chaos, where "teachers are confusing or contradictory, fail to communicate clear expectations and directions, and ask for outcomes without articulating the means to attain them" (Jang et al., 2010, p. 589).

Involvement versus rejection and neglect. The third type of support, derived from people's need for relatedness, is involvement. Involvement refers to "the quality of the interpersonal relationship with teachers and peers; its opposite is rejection or neglect" (Skinner \& Belmont, 1993, p. 573). It is provided through "warmth (or the ability to amicably connect with others and to partake in mutually enjoyable activities) and responsiveness to distress (or the ability to empathize with and respond to others' unpleasant feelings in a way that provides solace and comfort)" (Vansteenkiste et al., 2010, p. 132). More precisely, it refers to behaviors such as taking time for, expressing affection toward, enjoying interactions with, being attuned to, and dedicating resources to someone, for example doctoral students (Deci \& Ryan, 2000).

\section{SDT in the analysis of advisors' supervision styles}

Surprisingly, SDT has very rarely been used to investigate advisors' supervision styles in the doctoral context. To our knowledge, only one piece of research has done this (Litalien, 2014). Yet SDT is a particularly relevant framework for investigating advisors' supervision styles, and this for at least three reasons.

First, it is one of the main theoretical frameworks used to analyze teacher support at other educational levels such as in compulsory and higher education. There is a large body of research inves- 
tigating, in the light of SDT, how teachers' supportive behaviors foster students' outcomes such as persistence, learning and performance (Vansteenkiste et al., 2010).

Second, it is interesting to observe that the three support dimensions of SDT correspond to a number of supervision dimensions identified in the doctoral literature. The "Ideal Mentor Scale" (Bell-Ellison \& Dedrick, 2008; Rose, 2003) covers three dimensions (integrity, guidance and relationship), which are reminiscent of autonomy, structure and involvement, respectively. The advisors' perspectives and roles identified by Barnes and Austin (2009) may also be related to the SDT dimensions. For example, collaborating and collegiality relate to autonomy; mentoring and honesty relate to structure; and accessibility, support/care and friendly/professional refer to involvement. Three of the advisor behaviors scale designed by Zhao et al. (2007) (academic advising, personal touch and cheap labor) are also reminiscent of structure, involvement and control, respectively.

Third, this framework is particularly relevant to doctoral work and its context. Firstly, the issue of autonomy versus control is predominant in the doctoral experience. Within the earlier education stages (compulsory education, higher education), although some room may be allowed for students' choices, the content and directions of the work are largely determined by teachers, programs, standards, and so forth. Similarly, few other professional occupations require employees to carry out a personal project over a period of several years. In the doctoral context, although some advisors are more controlling than others, the final responsibility for specifying a research question, working on it for a period of several years, ensuring it progresses, and being able to present and defend it in front of other scholars at the end is the responsibility of PhD students. A sense of autonomy and self-determination is therefore central in this process. Advisors' support for autonomy may therefore lead to increased motivation and engagement, while a controlling style may lead to doctoral drop-out. Secondly, when confronted with the typical challenges of doctoral work, that is, uncertainty, disappointment (e.g. non-significant results), and/or criticism (e.g. from peers and reviewers), PhD students' sense of competence is likely to vacillate. Yet, at the same time, feeling competent will play a central role in allowing the students to complete their PhD. A structured - and not chaotic - style from the advisor is therefore likely to be crucial in helping students to complete their $\mathrm{PhD}$. Thirdly, $\mathrm{PhD}$ students have a special relationship with their supervisor: a relationship that is one-to-one, long-lasting, in which the supervisor plays both a formative and an evaluative role, and in which both protagonists face different and sometimes opposed challenges and constraints. The quality of the relationship between the two will therefore be crucial in ensuring a successful collaboration.

Fourth, and finally, the research on doctoral students often reports a tension between their need for guidance and autonomy and considers those two needs as opposing forces (e.g. Gardner, $2007,2010)$. On the one hand, doctoral students are happy to be independent, to be allowed freedom to choose their own direction, to use their own motivation to guide them, and to have a supervisor who is not a "control freak" constantly "looking over your shoulders" (Gardner, 2007, p. 733). But, on the other hand, this independence is sometimes a bit too much for them, they feel "left alone" or "lost" and wish they had received "a little more feedback and supervision" (Gardner, 2010, p. 71). The distinction offered by SDT between structure and autonomy allows for consideration of these two needs as independent and complementary dimensions, and therefore of the prospect of needing and receiving both autonomy and structure.

\section{Aims of the Present Study}

The general aim of the present study is to analyze doctoral supervision in the light of selfdetermination theory. More precisely, we confront doctoral supervision practices to the three types of support described in the basic needs theory (BNT), which is one of the "mini-theories" composing self-determination theory (SDT). Doing so, we are pursuing two objectives. 
On the one hand, we use these three types of support (involvement, structure and autonomy support) as an analytical framework to categorize the advisors' supervisory practices described by doctoral students. This first objective makes three contributions to the existing knowledge. First, it tells us whether this theoretical framework is relevant to reflect supervisory styles in the doctoral context; that is, whether these practices correspond to the definition of these three dimensions and can be categorized according to them. Second, it offers to the theory an illustration of how doctoral supervisors offer involvement, structure and autonomy support to their students, that is, how these types of support are embodied in this particular context. Third, it offers to the field lists of practices that correspond to these three types of support and that, according to the theory, are likely to support doctoral students' needs and therefore raise/trigger/lead to positive motivational outcomes. These lists of practices may therefore be used in doctoral supervisors' training or in order to develop questionnaires of doctoral support based on the SDT.

Conversely, we discuss the theory in the light of the present material and context. Categorizing the doctoral supervisory practices into the three categories of support will lead us to question and discuss limitations and avenues for reflection about this theoretical framework. Confronting the SDT framework with this new context will stimulate reflection and outline paths for the future development of the SDT.

\section{Method}

\section{Data Collection}

\section{Sample and context}

In our national context, doctoral students are supported by a supervisor (who is on a tenure track), sometimes a co-supervisor (typically a post-doctoral student), and a committee that they meet once per year. The doctoral process lasts 4 years if the doctoral students are on a research grant and therefore work full time on their research or 6 years if the students are research assistants and therefore work part-time on their research and research and part-time on their teaching.

In the present study, we conducted interviews with 21 former PhD students. Their names were changed in order to ensure anonymity and their characteristics are presented in Table 1. We conducting interviews until the point where: (1) our sample reflected the common and diverse characteristics of $\mathrm{PhD}$ students in our context; and (2) adding new participants offered little new information. First, we sampled participants so that they reflected both prototypical profiles of $\mathrm{PhD}$ students and the diversity of experiences and contexts $\mathrm{PhD}$ students are likely to work in. Diversity and balance were sought for the issue of the $\mathrm{PhD}$ ( 8 completers and 13 departers), their $\mathrm{PhD}$ the discipline of their $\mathrm{PhD}$ ( 8 from Sciences \& Technology, 7 from Social Sciences, 6 from Health Sciences), the type of funding they received ( 7 on research grants, 13 in research assistant positions, 1 without funding), their gender (12 women, 9 men), and the university they were working in. Second, we used saturation as a guiding principle. We kept interviewing new participants until reaching the point of diminishing return, which is the point where we started to recognize patterns in the participants' experiences and where adding more data offered little new information. Paraphrasing other authors, Mason (2010) explained that this is "the point where it becomes 'counter-productive' and that the 'new' that is discovered does not necessarily add anything to the overall story, model, theory or framework" (p. 2) 


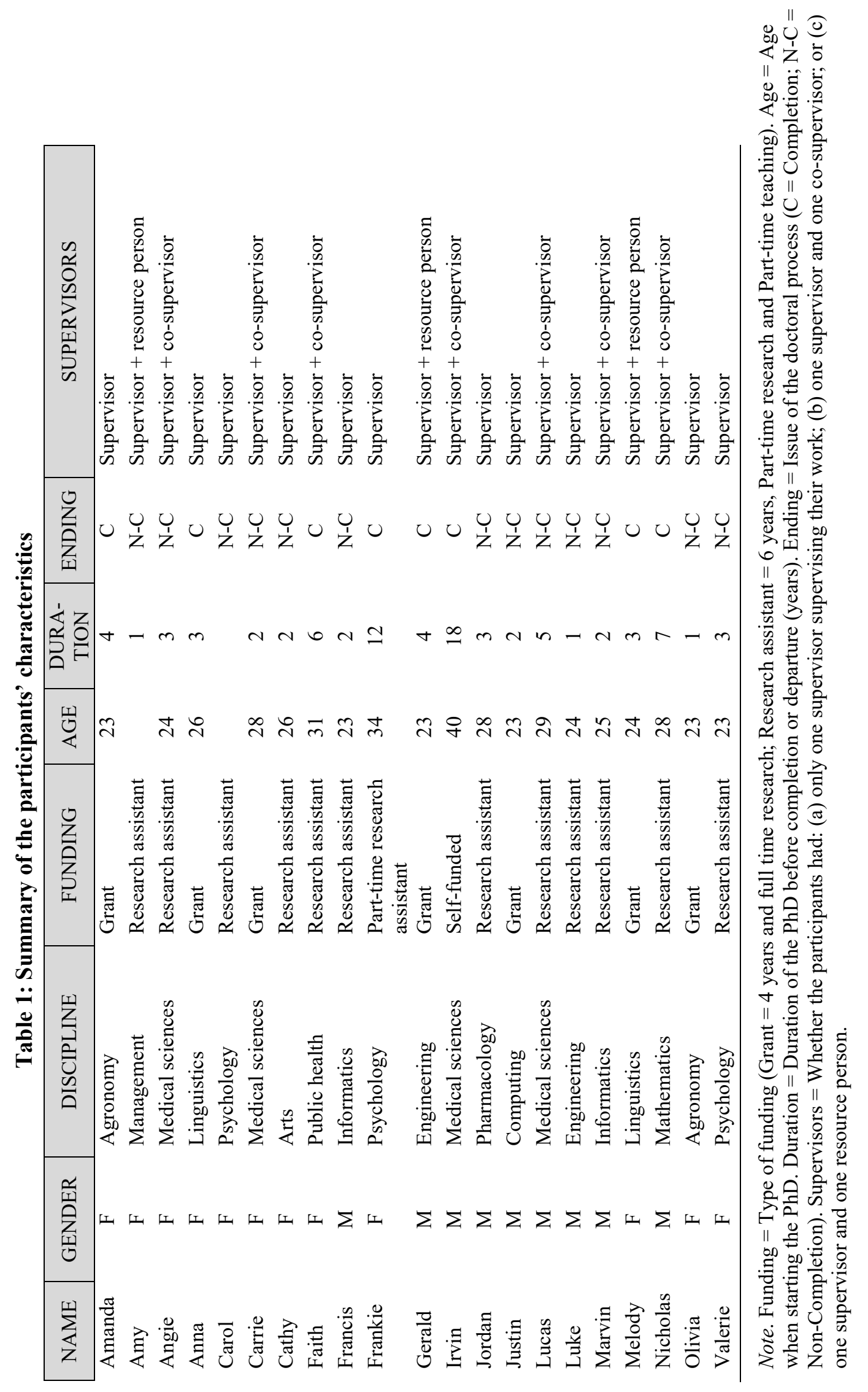


Furthermore, this number of 21 participants corresponds or exceeds the number of participants generally used or recommended in studies using content analyses. For example, Bertaux (1981) argued that fifteen is the smallest acceptable sample size in qualitative research and Mason (2010) observed that studies that use content analyses generally rely on 2 to 30 interviews (mean $=28$ ). Finally, other authors tie their recommendations to heterogeneity and research objectives. For example, Kuzel (1992) recommended "six to eight interviews for a homogeneous sample and twelve to twenty data sources when looking for disconfirming evidence or trying to achieve maximum variation" (Guest, Bunce, \& Johnson, 2006, p. 61). Given that our study focuses on a rather homogeneous group and had precise objectives, 21 participants appeared to be an adequate number.

\section{Procedure}

The three first authors of the present article conducted the interviews. They took place in the researchers' offices or in the participants' offices or houses. An interview protocol was designed and composed of the four following steps. First, the interviewer provided the participants with a short introduction to the study and its ethical considerations (e.g. freedom to withdraw at any time). Second, following the designs used by Vekkaila, Pyhältö and Lonka (2013) and Meijer, de Graaf and Meirink (2011), we based the interviews on participants' own sketches of their individual doctoral journeys. We presented participants with graphs that illustrate developments and changes over time. These pictures were taken from Leclerc-Olive (1997) and represent orthogonal axis with lines departing from the origin and taking different shapes and directions (e.g. a straight diagonal arrow, a wavy line, a dotted and broken line, an upward and then downward line, and so forth). We then invited the participants to sketch the line(s) representing their own doctoral journey. Third, this drawing was used to support the subsequent discussion and sharing of experiences. The first question was to ask the participants to explain what they had drawn. Later during the interview, three other large open-ended questions were formulated: "What was a $\mathrm{good} / \mathrm{bad}$ day for you during your PhD?" and "Have you ever considered quitting your PhD?". Between the open-ended questions, the discussion developed freely between the participant and the interviewer, punctuated by follow-up questions from the interviewer (e.g. what happened exactly, who was implicated, how did you feel, what did you do). The purpose was to address "what" and "how" questions and to understand the participants' experience from their own point of view (Blanchet \& Gotman, 2012). We also had a thematic guide with a list of themes that had to be addressed in the interview (e.g. relations with the supervisors, teaching assignments). These were addressed at the end of the interview if they had not been previously raised (Hsieh \& Shannon, 2005). The interviews lasted about one hour and were recorded. They were transcribed according to the guidelines of McLellan, MacQueen and Neidig (2003) and Oliver, Serovich and Mason (2005). Notes were taken by the interviewers before and after the interviews (to be aware of our possible biases and to write down our spontaneous impressions, respectively).

\section{Data Analysis}

The data were analyzed using a thematic analysis approach (Boyatzis, 1998; Braun \& Clarke, 2006; Fereday \& Muir-Cochrane, 2006; Vaismoradi, Turunen, \& Bondas, 2013). Thematic analysis is "a method for identifying, analyzing and reporting patterns (themes) within data" (Braun \& Clarke, 2006, p. 79). This method is used to organize and describe the data in rich detail, and to interpret various aspects of the research topic (Boyatzis, 1998; Braun \& Clarke, 2006).

First, data were read and listened to several times, writing down initial ideas for the coding and analysis. Second, codes and larger themes were identified. Several authors have pointed out that codes and themes can be identified either in an inductive or deductive way (Braun \& Clarke, 2006; Hsieh \& Shannon, 2005; Gilgun, 2005). In the present study, we used a deductive ap- 
proach, which is referred to as "directed content analysis" (Hsieh \& Shannon, 2005) or "deductive qualitative analysis" (Gilgun, 2005). This approach is to be used when an "existing theory or prior research exists about a phenomenon that is incomplete or would benefit from further description" and when the aim of the analysis is to "validate or extend conceptually a theoretical framework or theory" (Hsieh \& Shannon, 2005, p. 1281) or, in other words, when the study begins with "a conceptual model for the purpose of testing it, refining it, or refuting it and coming up with a better set of concepts and hypotheses" (Gilgun, 2005, pp. 41-42). In this approach, the initial coding of the data is based on a theory and, during the data analysis, "the researchers immerse themselves in the data and allow themes to emerge from the data" (Zhang \& Wildemuth, 2009 , p. 2). Following this approach, we relied on the central concepts of SDT and Appleton's model of engagement (Appleton, Christenson, \& Furlong, 2008; Deci \& Ryan, 2000) to determine our initial coding categories and to identify operational definitions for each category. Individual themes were coded into these categories and data that could not be coded into them were analyzed "to determine if they represented a new category or a subcategory of an existing code" (Hsieh \& Shannon, 2005, p. 1282). Progressively, new coding categories were therefore created and the definition and label of the existing code were modified in order to reflect the themes related to these categories emerging from the particular context of the $\mathrm{PhD}$ (Miles \& Huberman, 1994).

This coding scheme was designed and validated progressively by two coders. A sample of the data was first coded by the two coders, who then discussed "doubts and problems concerning the definition of categories, coding rules, or categorization of the specific cases" (Schilling, 2006) in order to improve the coding scheme. This iterative process was implemented until sufficient coding consistency was achieved (Weber, 1990). Finally, after coding the entire dataset, the consistency of the coding was rechecked by proofreading the definition and content of each of the coding categories. Finally, we interpreted the content of these categories. This interpretation is presented in the results section below.

\section{Results}

The first aim of the present study led us to list the doctoral advisor's supporting practices corresponding to the definition of the three support dimensions from SDT, and therefore to illustrate how supervisors offer autonomy support, structure and involvement to the doctoral students. The second aim of the study led us to consider three directions for development of SDT: (1) the issue of supervisory practices (labeled "encouraging achievement") which relate both to involvement and structure; (2) the danger of supervisors confusing structure and control (and confusing autonomy and chaos); and (3) the suggestion that the seedbed for offering positive supervision is the level of trust that the supervisors have in their PhD students. A summary of the results is presented in Figure 1.

On the on hand, we illustrate the six SDT supervising styles with practices from the doctoral context. On the other hand, we provide three avenues for reflection on SDT: (a) the set of practices (labeled as "encouraging achievement") that belong both to structure and involvement, (b) the risk that supervisors' intentions for structure and autonomy turn into controlling and chaotic practices, respectively, and (c) the suggestion that trust is an enabling condition for offering autonomy, structure and involvement to the students. 


\begin{tabular}{|c|c|c|c|}
\hline \multicolumn{4}{|c|}{$\underset{\text { (c) }}{\text { Trust }}$} \\
\hline \multicolumn{2}{|c|}{ INVOLVEMENT } & STRUCTURE & Control \\
\hline $\begin{array}{l}\text { - Showing interest for } \\
\text { the person } \\
\text { - Emotional support } \\
\text { - Friendship } \\
\text { - Same wavelength }\end{array}$ & $\begin{array}{c}\text { (a) } \\
\text { Encouraging } \\
\text { achievement } \\
\text { - Caring about how } \\
\text { the PhD student is } \\
\text { doing with his work } \\
\text { - Being positive about } \\
\text { their work } \\
\text { - Recognizing efforts } \\
\text { - Standing by them } \\
\text { vs. } \\
\text { - Negative judgments }\end{array}$ & $\begin{array}{l}\text { - Regular supervision } \\
\text { - High quality feedback } \\
\text { - Answer to specific } \\
\text { questions } \\
\text { - Expertise } \\
\text { - Instrumental help } \\
\text { - In-depth discussions on } \\
\text { the research project } \\
\text { - Devoting time }\end{array}$ & $\begin{array}{l}\text { - Controlling research directions } \\
\text { and daily work organization } \\
\text { - Time pressure } \\
\text { - Overt or covert control } \\
\text { - "Double binds" }\end{array}$ \\
\hline \multicolumn{2}{|l|}{ Rejection } & Chaos & AUTONOMY \\
\hline \multicolumn{2}{|c|}{$\begin{array}{l}\text { - Hostile behaviors } \\
\text { - Conflicting or cold attitude }\end{array}$} & $\begin{array}{l}\text { - Leaving students alone } \\
\text { - Contradictory demands }\end{array}$ & $\begin{array}{l}\text { - Offering opportunities to } \\
\text { choose directions }\end{array}$ \\
\hline
\end{tabular}

Figure 1: Summary of the main results

\section{First Aim: Analysis of Doctoral Supervisory Practices in the Light of SDT}

\section{Autonomy support versus control}

While participants rarely mentioned autonomy-supportive practices from their supervisor, controlling practices were found to be a central source of concern in their experience.

The typical sequence of a controlling interaction is the situation presented hereafter. First, the supervisor has a strong opinion on how to do something. For example, s/he considers that it is important to collect data quickly without spending too much time reading articles or refining the data collection method (Valerie, Anna), s/he is sure that the current research direction is the best and that the best option is to pursue it even if the results were not successful during these last years (Nicholas), and so forth. Second, the supervisor intrudes in the $\mathrm{PhD}$ students' work and pressures them to think or behave in a specific way, which differs from their preferred approach, often without offering any rationale for it. For example, a $\mathrm{PhD}$ student in Linguistics explains how her supervisor intruded into her way of working in order to pressure her to work in a different manner: "Sometimes he told me 'stop asking yourself those questions', it doesn't make sense, it's useless'... Because...basically, he is not much into theory...He did not see the point of my questioning, which was sometimes very... Well, I studied another discipline before, and I learned a specific research method there. And he was telling me 'You can't do it this way, you can't use a method from this other discipline to do research in Linguistics, that's not how we work here'. I was a bit disappointed, because it was my method. I knew it was a good method, and that's how I wanted to do it" (Anna).

The target behavior may relate to: (1) the directions taken in the doctoral research (e.g. using a specific questionnaire, investigating a specific direction, engaging in a side-research project which is more valuable for the supervisor); or (2) the way the PhD students organize their daily 
work (e.g. prohibiting home working or listening to music when working, requiring them to keep the office door open all day long, cancelling a day off). For example, in the following excerpt, Valerie explains that she suffered from the fact that her supervisor did not let her work from home: "Some days, I stayed at the office until $10 \mathrm{pm}$. The day after I arrived later or I felt like working from home. This also played a role [in my dropping out]; she did not like us working from home, because she had had a bad experience with a former PhD student, who worked a lot from home and dropped out of her $\mathrm{PhD}$. And so we were very rarely allowed to work from home, and I suffered a lot from that because I worked much better at home, at least for writing".

Imposing time pressure may also be one of the controlling behaviors (e.g. tight deadlines, requirement to do more and more work before the deadline, publishing more and quicker). In the following example, a $\mathrm{PhD}$ student in medicine explains how his supervisor and co-supervisor intruded into his preparation of the coming meeting with the thesis committee, asked him to change everything at the last minute, which ended in a profound experience of failure at the meeting: "They said to me 'You need to check all your results and work on it all over again' (...).

They did that four days before my committee meeting. So, four days before, changing everything, thoroughly reconsidering the way to present it, well it doesn't work. And the day before my committee, my supervisor popped into my office and gave me a new article that she thought I should read and relate to my results... And ... Well it did not make any sense ... My presentation was not ready yet ... and doing this new reading ... well ..." (Lucas).

The types of pressures that are exerted on PhD students may be direct when their content is socially acceptable (e.g. keep searching in this direction even if you are stuck and do not find any interesting results for a long time), or indirect when the content crosses boundaries of what is socially acceptable (e.g. doing some work or attending a conference during a maternity leave, collecting data from children while being pregnant). For example, Valerie explained how her female supervisor applied indirect pressure on her to do some work during her maternity leave: "My supervisor was talking a lot about herself: 'Five days after I gave birth I was attending this congress', 'I left the baby with my mother', to send me the message 'You should attend this and that conference'... 'By the way, would you like to attend this conference?'... She was not insisting, but she said it once, twice, three times ... I also had to work on something - I don't remember what - during my maternity leave ... Well 'had to', I 'agreed to', but I was annoyed because I wanted to be left alone ... It was rather insidious ... like 'I did this, I did that', she was always talking in the first person. And after a while I became fed up hearing it because I knew that these were all implicit messages, which I had to decode" (Valerie).

Controlling behaviors sometimes lead to even more toxic relationships when they turn into "double binds". In this type of situation, even if the PhD students follow one of the requirements of their supervisor, they will fail to meet another of his/her recommendations. Lucas illustrates this by explaining about his co-supervisor that "On the one hand, she criticizes us for not making enough suggestions, but when we do make suggestions, they are never good enough, never what she expected".

\section{Structure versus chaos}

Participants made extensive reference to their supervisors' structuring behaviors, either because they were happy to benefit from those behaviors or because they were frustrated that these practices were too rare or non-existent. The aspects mentioned below are the indicators of structure that were mentioned by the participants.

First, a structuring supervisor has time available to discuss their projects with $\mathrm{PhD}$ students (as opposed to being involved in so many time-consuming activities and responsibilities that $\mathrm{s} / \mathrm{he}$ has little time left for the $\mathrm{PhD}$ students), offers regular supervision (e.g. regularly asks $\mathrm{PhD}$ students 
how they are doing with their work, suggests meeting up to discuss the research) and sets energizing short-term and mid-term objectives for their work. Conversely, $\mathrm{PhD}$ students are sometimes left alone with their work for weeks or months, which often happens when $\mathrm{PhD}$ students are research assistants and are therefore also busy with teaching assignments in addition to their research work. For example, Amy regrets that her supervisor did not have enough time to supervise her: "He answered my e-mails only very briefly, and he had little expertise in the area so ... When you don't know much about the subject and you have very little time, it is not easy to mentor someone ...".

Second, a structuring supervisor is responsive to $\mathrm{PhD}$ students' requests for feedback (e.g. on a text that has been written), and rapidly gives a feedback that is relevant (as opposed to off the topic), in-depth (as opposed to quick and superficial), rigorous and constructive (as opposed to overly positive) and consistent (as opposed to inconsistent, for example suddenly stating that the direction of the research is wrong although this has never been mentioned before). Further, the supervisor answers the specific questions that the $\mathrm{PhD}$ student asks and suggests relevant directions and advice for the research. For example, Anna reported that she lacked such feedback from her supervisor: "When I had written something, I submitted it to him and waited for his feedback ... And, generally, he corrected my use of language, he edited the style, he showed me my mistakes, you see. And he did not really answer my questions. Or, he was trying to help, asking 'Have you read that?' but it was not relevant". Relevant feedback is related to the level of competence and expertise of the supervisor with regard to the thesis's topic. For example, Melody stated that "My supervisor had limited expertise in ... Well, I had to use specific methods, statistics, etc. and he was not into it. He became my supervisor because he was working in the field but ... And so every time I did something, he was like 'Yeah, that's great, it's good, it's good!'. I never had an in-depth or a constructive comment".

Finally, the supervisor may play a crucial role in: (1) helping the students in "containing" their work, that is, remaining focused on one research direction and not spread themselves too widely in the literature; (2) offering instrumental help (e.g. suggesting questionnaires to be used, helping to write parts of the manuscript); and (3) offering administrative help to the students (e.g. with the documents that need to be completed for the doctoral school).

On the basis of what has been mentioned above, we can see that what is particularly important for $\mathrm{PhD}$ students is that their supervisor "gets his hands dirty" with offering in-depth feedback on written work or thorough discussion of the research project. Amy illustrates this lack of in-depth feedback: "If you write something which makes the student feel that you did not really read it ... Or if you print the document and sketch some comments on it because 'he needs some support but you lack time to supervise him/her for this or that reason'... well ... (sigh). PhD students feel all that. We know when someone has read our work or not. We know whether someone read it and did not understand something, or if s/he just leafed through the document and that's it". Another $\mathrm{PhD}$ student remembered the time when he finally sat down at the table with his supervisor and co-supervisor and had a very useful discussion of his mathematical model: "One of the supervisors told me 'We will check the model from A to Z'. And how long did it take? Fifteen minutes, seriously. We checked it together and he told me 'There are two things'. He told me 'There, you can write it this way', something that I didn't know. And with the second, we found an error in one part of the model. He told me 'You can't do it this way; you need to do it that way'. And that was it, the problem was solved" (Nicholas).

Conversely, participants also mentioned instances of chaotic support. Lucas, for example, explains about his co-supervisor that "So it's like anything and everything. One day, she tells me something and, the day after, she tells me the opposite. (...) I did not understand what they expected from me anymore. Because they asked me to do different things, because they do not even agree with each other ... After a while, you're just lost, you know". 


\section{Involvement versus neglect}

With regard to involvement support, participants described both their supervisors' behavior and the relationship that they had with them.

First, participants identified several involvement practices displayed by their supervisors. A first such practice is showing interest in them as a person and not only as a worker. For example, Angie recalls about her supervisor that "We did not feel that he cared about us, you know, he never asked 'How are you?' or things like that. These are small things but they make you feel that you are more than two hands executing a job, that you are a person. Stopping two minutes to ask "how you are doing' makes you feel like a real person. But he did not see things that way".

Other involvement practices valued by the participants are: reassuring them in case of stress, taking time to listen to them, and trying to sort things out when they are facing a relational or emotional problem (e.g. being in conflict with another member of the team, suffering from loneliness in an isolated office). For example, Angie stated that "I had some constructive discussions with my supervisor when I was encountering problems with my co-supervisor. One day I gathered all my courage and went to my supervisor to discuss these issues. He was receptive to it, which contributed to improving my perception of him. I said to myself that behind his cold appearance, it was possible to discuss my problems with him. He may not come to me to ask me how I am doing, but if I go to him to tell him that I am not doing well, he listens. It turned out that he had no solution to propose for this given problem, but at least he had listened to me".

Conversely, doctoral students also experienced perceived adverse behaviours from their supervisors, such as an unpleasant tone when talking to them, unfriendly comments, abrupt interactions and formulations of requirements, aggressive attitude, being shouted at when they did something considered as wrong by the supervisor, and, at the extreme, being psychologically or sexually harassed (e.g. isolation, seduction, ruining reputation). For example, Angie says of her supervisor that "He was rather unpleasant with me. It was particularly noticeable during meetings. I felt like when it was my turn to talk, the tone of his voice changed a bit. I don't know ... there was no chemistry".

Second, participants also characterized the relationship that they shared with their supervisor. These relationships ranged from conflicted ones to friendship (i.e. having fun together, going out together outside work). For example, Gerald reported that "We were like friends, which allowed us to see each other outside work, to have a drink, to attend a thesis defense and to stay there until the end of the evening, discussing everything". The advisor-advisee relationship may also be "professional only" and therefore rather cold (i.e. sharing only work-related discussions, not inquiring on how the person is doing more generally). For example, Luke reported that "He was my boss and that's it. No close relationship for sure. Our relationship was rather distant ... We did not get on particularly well ... It was a purely professional relationship. This is it I think, I don't know (laugh) ... When I compare it to other PhD students who shared rather close relationships with their supervisor, I realize that it's not the type of relationship that developed between us. I know that some doctoral students even share friendly relationships with their supervisor. Here not at all. There was a distance between us. I felt that he was the boss and I was there to work in his team. There was no way we could have become friends or anything that was very clear".

The PhD students particularly appreciated being on the same wavelength as their supervisors. Inversely, a large gap between the doctoral students and their supervisors with regard to their lifeand work-related views and values, their aspirations for the doctoral work, or the supervision (i.e. incongruence between the supervision offered and the students' needs and expectations) may impair their collaboration in the long run. For example Valerie stated that "I started to see a discrepancy with my supervisor, I realized that we did not see life the same way, we did not have the same priorities. I started to think 'well, it is your choice, I am not judging you, but I am not head- 
ing toward a career like yours, this is not what I want'". This finding may be interpreted in the light of the Person-Environment (P-E) fit framework (Edwards, 2008; Pyhältö, Vekkaila, \& Keskinen, 2012). Fit is defined as "the congruence, match or similarity between the person and environment" (Edwards, 2008, p. 168) and it plays a role in students' and workers' satisfaction and achievement (Kristof-Brown, Zimmerman, \& Johnson, 2005).

\section{Second Aim: Questioning SDT in the Light of the Data}

The second aim of the present study was to discuss our theoretical framework in the light of our data and context. The data led us to question the support dimensions depicted in the SDT in the three following ways. First, we observed that some supervision practices (labeled "encouraging achievement") referred to both structure and involvement. This finding therefore questions the belonging of this important type of practices in the SDT dimensions, and underlines the risk of overlooking or setting them aside in future research as they are at the frontier between the two. Second, we observed that, in practice, intends to offer structure or autonomy may easily turn into control or chaos practices. We therefore discuss the proximity of these two dimensions and the danger of slipping from the first to the second. Third, we came to the hypothesis that a necessary condition for supervisors to be able to offer positive support to their doctoral students may be that they trust their competence, efforts and likelihood of $\mathrm{PhD}$ completion.

\section{Practices referring to both structure and involvement}

Involvement focuses on the warmth of the human relationship while structure refers to the guidance offered for performing a given task. There was one set of practices that was difficult to place in either of these two categories because they referred to both. These practices are named "encouraging achievement" below and are represented at the intersection of the two types of support (structure and involvement) in Figure 1.

These practices include interpersonal support aspects (e.g. warmth, expressing affection) but that refer only to the research task itself. They therefore relate to involvement as they include warmth, responsiveness to distress, expression of affection, enjoyment of interactions, and so forth, but depart from it as they do not only refer to the quality of the relationship in itself, but to a warm relationship within a discussion on the dissertation and its progression. On the other hand, these practices also relate to structure as they refer to the thesis work and they promote perceived competence, but they are beyond the spectrum of structure as such as they depart from genuine structuring of the work and are strongly colored with involvement aspects.

An example of these types of practices is caring about how the $\mathrm{PhD}$ students are doing with their work. For example, Gerald recalls that he enjoyed "The presence of the supervisor, who was asking for results ... Well, asking for results is not the right term. He was not requiring results, but caring about how I was doing, how the research was going. My co-supervisor was the same. They were in the office next door and did not hesitate to come and ask if everything was going ok."

Another example is being positive about the $\mathrm{PhD}$ students' work (e.g. letting the $\mathrm{PhD}$ students know that they are doing a good job, providing positive feedback and encouragement, congratulating them when they do something particularly well) and letting the $\mathrm{PhD}$ students know that they are going to be fine and/or succeed in an upcoming challenging task (e.g. intermediate reports, $\mathrm{PhD}$ defense meeting).

On the contrary, the supervisor may communicate negative feedback and general, as well as negative judgments (e.g. "When you are permanently told that your work is not progressing, that you're not working enough, that you're doing nothing, that you're not good enough, well, yes, there are times you feel like giving up" (Lucas)). The supervisor may also fail to offer recognition for the work that has been done (e.g. acknowledging the quantity and quality of work that has 
been agreed on a study even if no significant results came out of it). For example, Angie explained that "With the first supervisor, when an experiment went wrong, I felt like it was my fault, while he [the second supervisor] did not judge my work .... Because not obtaining significant results in an experiment does not mean that you have not been working hard on it. And this was often the case [with the first supervisor]. In fact, I had said this to him, that I felt that when there were no results with an experiment, he seemed to think that I had not put enough effort into it. But it is just not the case, you know".

Finally, a specific supervision attitude that appeared to be important in the PhD students' experience is their perception that their supervisor stands by them even in the face of weaknesses or failures, for example, recurring non-significant results, criticism from other academics of their work (e.g. during thesis committee meetings), rejection of a paper, and so forth. This seems to be of particular importance for $\mathrm{PhD}$ students. They need to feel that their supervisor is on their side even when facing obstacles or failures, and report high levels of distress when they feel that their supervisor is turning their back on them when they are facing such experience of failure. For example, Valerie remembers that her supervisor let her down in front of the committee members during a committee meeting: "And when I saw my supervisor letting me down in front of them, asking 'Well yes, why did you do that?', I said to myself 'No, it's not possible anymore, I can't keep working with someone who is playing a double game'. It has been very hard for me to see my supervisor saving face in front of her colleagues and choosing to put me down. This was the point of no return."

In sum, all of these practices refer to involvement practices (e.g. warmth, expressing affection), which are expressed with regard to the PhD students' advancement and success or failure experiences in their work (e.g. during feedback situations). The involvement and structure aspects are therefore intertwined in these practices, which are therefore suggested to relate to these two categories of support.

\section{Confusion between structure and control}

Autonomy and structure were found to be of central importance in promoting PhD students' motivation and engagement. Yet, it also appeared that the border between the autonomy and structure is a fine line. Socializers who wish to provide structure may actually offer (or perform actions that are perceived as) control. For example, a supervisor may wish to avoid that their doctoral students are at sea in their research and so provide them with structure (e.g. promising research directions, clear expectations, explicit and detailed information on how to achieve these objectives, and so forth). Yet, these good intentions may quickly turn into prioritizing his/her perspective over the $\mathrm{PhD}$ students' one, neglecting their doubts or opposition against these directions, and pressuring them to behave according to his/her requirements. For example, according to Anna, her supervisor had it in mind to encourage her progress in her work, but this intention turned into a controlling pressure: "I think that he saw his role as kicking me in the behind, but, me, I needed to explore different directions. And this ... sometimes I was disappointed by him".

Several characteristics of the doctoral context make it particularly prone to this confusion between structure and control. First, whereas in the school context the standards and content of the program are defined by external/higher authorities, in the doctoral context, although some criteria exist (e.g. one published article), the content, directions, purposes, are to be chosen and negotiated between the supervisor and the doctoral students. There are therefore more decisions to be taken and more opportunities for the intention of structure to turn into control. Second, PhD students maybe have particularly high needs for autonomy. They are not students any more but researchers, and this new role calls for more autonomy in their work. Further, the intrinsic nature of research work requires a high level of appropriation of one's work and therefore a sufficient level of autonomy to allow this appropriation to take place. Because of this strong need for autonomy, 
a structuring attitude from the supervisor may be considered by $\mathrm{PhD}$ students as attempts to control them.

\section{Trust as a seedbed for support}

Finally, these results raise the following question: what enables supervisors to provide their doctoral students with autonomy, involvement and structure? Inversely, what leads supervisors to adopt behaviors that thwart their students' basic needs? Despite the importance of this question, it appears that it has rarely or never been addressed in the literature. Several factors may lead supervisors to adopt one supervision style or another; for example, their personality, their beliefs about good supervision, their concerns and priorities in their own work, and so forth. On the basis of our material, we suggest that one of these antecedents is the level of trust that supervisors have in their doctoral students, that is, the extent that supervisors trust their students' competence, involvement and likelihood of $\mathrm{PhD}$ completion. This construct of trust appeared in the background of what doctoral students told us about their supervisor. The supervisory relationship of the participants whose basic needs were satisfied appeared to be based on mutual trust. Despite common difficulties, the students' competence and involvement were not questioned. In contrast, the supervisory relationship of the participants whose basic needs were thwarted appeared to be colored with doubt, suspicion and permanent questioning of the students' involvement and quality of the work done. For example, Angie remembered that "I feel like my supervisor thought that I wasn't doing a damn thing, but that was not the case. I agree that the results weren't there but it was not due to a lack of engagement". Valerie also reported suffering from having a supervisor "who still saw me as a student, who did not trust me, who was still testing me, to whom I still had to prove my abilities".

This assumption is in line with the growing body of research investigating the effects of trust in other contexts. In educational literature, recent studies have highlighted the positive role of teachers' trust in their students for the students' achievement (Goddard, Tschannen-Moran, \& Hoy, 2001; Meirieu, 2008; Van Maele \& Van Houtte, 2011; Watson \& Ecken, 2003). In organizational psychology, research has stressed the importance of managers' trust in their subordinates for persistence and productivity in individuals and organizations (Brower, Lester, Korsgaard, \& Dineen, 2009; Colquitt, Scott, \& LePine, 2007).

In this last body of research, trust is commonly defined as "the willingness of a party to be vulnerable to the actions of another party based on the expectation that the other will perform a particular action important to the trustor, irrespective of the ability to monitor or control that other party" (Mayer, Davis, \& Schoorman, 1995, p. 712). Applied to the doctoral context, it would reflect that supervisors agree to be vulnerable to the actions of their doctoral students based on the expectations that they will perform actions such as doing a given task well or completing their dissertation. Further, Mayer et al. (1995) review the literature on the antecedents of trust and identify three recurrent components of trustworthiness: trustees' ability (i.e. the skills and competencies in a specific domain); benevolence (i.e. the will to do good to the trustor); and integrity (i.e. the adherence to a set of principles that the trustor finds acceptable). We suggest that the first element, ability, is particularly important in the doctoral context.

High levels of trust have been show to lead to more positive and less suspicious views of others (Weibel \& Six, 2013), as well as to more social exchange relationships, risk taking and citizenship behaviors (Colquitt et al., 2007). Further, recent work from organizational and trust literature suggested that "trust theory has the potential to complement self-determination theory in important ways" and that "supervisor's trust in the employee is an important variable in the framework" (Weibel \& Six, 2013, p. 67). According to these authors, supervisors' trust is likely to reduce suspicious monitoring of employees, and therefore to increase intrinsic motivation and cooperation. On the basis of our results, we could make the hypothesis that trust enables supervisors 
to provide autonomy, structure and involvement to their doctoral students. First, supervisors who trust their students are likely to be confident that the latter are able to make good choices in their $\mathrm{PhD}$ and therefore to offer them more autonomy. Second, supervisors who experience trust are also likely to feel more confident and relax, and therefore more likely to be warm and caring. Third, because these supervisors trust their students' ability, they are likely to behave in a way that makes the students feel more competent (e.g. displaying higher expectations, investing more time in them, offering more detailed feedback). For example, Gerald explains that to be chosen by his supervisor to engage in a $\mathrm{PhD}$ with him meant that his supervisor trusted his abilities, which made him feel confident and competent. When asked what played an important role in his doctoral journey, he answered "Maybe also trust ... Well, this was maybe unconscious but having someone who tells you 'I appreciate working with you and I would be happy to do a PhD with you', it also played a role". This is in line with theories about self-fulfilling and the Pygmalion effect, which suggest that one's expectations about a person can eventually lead one to behave in accordance with these expectations, and that person to behave and achieve in ways that confirm those expectations (Brower et al., 2009; Van Maele \& Van Houtte, 2011).

Conversely, supervisors who mistrust their students are likely to discredit the choices made by the students and to pressure them to act in accordance to their own will (control). For example, Valerie recalls that "We were not allowed to work from home, and I suffered a lot from it, because I worked much better from home, and because I had the impression that she did not trust me". Considering that students are not going to perform expected actions is also likely to affect the quality of the relationship between the two, which gets colored with suspicion, reproaches, blames, frustrations, and rancor. Finally, lack of trust is likely to lead supervisors to adopt behaviors that make students feel incompetent. For example, Lucas reports about his co-supervisor that "It is so hard for her to trust people that ... This experiment I was talking about ... She asks me to do it. But she does not trust me at all, so she asks someone else to do it, and then to someone else, and then someone else, until she obtains a result she is satisfied with. It is very disturbing".

In sum, our material leads us to formulate the hypothesis that trust may be a crucial antecedent of structure, involvement and autonomy support. Supervisors who experience high levels of trust and expectation will be in a good position to offer constructive support, leading to positive outcomes in their PhD students. Conversely, a growing feeling of mistrust is likely to worsen the relationship, to preclude supervisors providing a supportive supervision style, to make $\mathrm{PhD}$ students doubt the quality of their work and their abilities and to lead them to consider quitting the doctoral track. This yet needs to be investigated in future studies, which would explicitly address the influence of trust on supporting styles among pairs of supervisors and $\mathrm{PhD}$ students.

\section{Conclusion}

The aim of the present study was to analyze doctoral advisors' supervising styles in the light of the three types of support promoted in self-determination theory and, conversely, to discuss SDT in the light of this new context and material. The first aim led us to illustrate how supervisors offer structure, involvement and autonomy support to the doctoral students, and to support the relevance of this theoretical framework in this particular context. The second aim led us to highlight three considerations about SDT that deserve future attention: the set of practices that stand between structure and involvement (e.g. encouraging achievement); the risk of confusion between structure and control (and between autonomy and chaos); and the hypothesis that trust may be a necessary antecedent for constructive support. These main results are summarized below and illustrated in Figure 1. We also discuss the limits of the present study and the related perspectives for future research. 


\section{Summary of the Main Results}

\section{First aim: analysis of doctoral supervisory practices in the light of SDT}

With regard to the first aim, the present study offers a list of valued supervisor practices corresponding to the three types of support described in SDT. First, although autonomy support is rarely explicitly mentioned, the participants extensively cited controlling practices. These direct or indirect pressures to follow a direction or behave in a way that did not make sense for the $\mathrm{PhD}$ students (e.g. with regard to the general directions of the research or to the way of organizing one's work) were associated with a negative emotional and motivational experience.

Second, the participants also make numerous references to structure, either being grateful for receiving such help or regretting not having benefitted from it. More specifically, they value the fact that their supervisor allocates time for meeting and discussing their research project, gives them relevant feedback, and help them structure and define their work; in sum, they expect a deep cognitive and behavioral engagement from their supervisor in their doctoral work. Conversely, they are disoriented when feedback and instructions for research direction change over time or from person to person.

Third, with regard to involvement, the participants value that their supervisor shows interest in them as a person, listens to them and reassures them in case of stress. Conversely, they are negatively affected by aversive behaviors such as unpleasant tone, unfriendly comments, and at the extreme, harassment. They also characterize the relationship that they share with their supervisor, in a range from friendly to cold/professional or even conflicting, and mention episodes of tensions or conflicts that they experienced and could or not be solved.

In sum, these behaviors are in line with and complement those found in previous studies, and this theoretical framework offers a new light to consider and understand them. Further, it is interesting to note that these supporting styles were found to be similar across doctoral students' types of funding and disciplines. While we were expecting that they would vary from one discipline to another (Gardner, 2010; Golde, 2005), we observed that the supporting practices described above occurred indistinctively across disciplines. More precisely, we found very different supporting styles and relationships, but we could not categorize and interpret them in the light of the disciplines. We therefore chose to analyze these results transversally in the present study. Nevertheless, this prevalence of common features over differences across disciplines and types of funding may be specific to our sample and context (universities, country) and therefore should be more deeply investigated in future studies.

\section{Second aim: questioning SDT in the light of the data}

With regard to the second aim, we found that the doctoral context and the content of our interviews questioned the SDT framework in three ways. First, we were confronted with a series of behaviors ("encouraging achievement") that belonged to both structure and involvement categories and referred simultaneously to those two types of support (e.g. being positive about the PhD students' work). This phenomenon also appears in factor analyses of quantitative questionnaires measuring these dimensions. Despite these being crucial behaviors in promoting motivation and engagement, there is thus a risk that they are overlooked and removed (e.g. from questionnaires or definition of the constructs) because of this overlap. It would therefore be interesting to acknowledge their existence and discuss the dimension they refer to. In addition, this result highlights the fact that the support categories are combined in practice (e.g. a supervisor might offer guidance with a warm or a neglectful attitude). It would therefore be interesting to investigate their interactions. In the literature, involvement is generally found to have a lower impact on stu- 
dents' outcomes than the two other dimensions. We hypothesize that the main role of involvement is to increase the positive impact of structure and autonomy. Involvement may be a necessary condition in order for structure and autonomy to have a positive influence on students' outcomes. It "oils" these processes, helping the reception of structure (e.g. critical feedback) and reinforcing the positive effect of autonomy. This should be investigated in future studies.

Second, our results highlighted the risk of confusion between structure and control; that is, the danger that an advisor who wishes to offer structure takes actions that are (perceived as) controlling. This confusion may happen in every context but is particularly prone to develop in a doctoral context. On the one hand, many choices need to be negotiated between supervisors and students and many opportunities for structuring support may therefore turn into controlling ones. On the other hand, students are likely to need particularly high levels of autonomy because of their status and the nature of their work. They are therefore more likely to consider behaviors that are intended to be structure as a form of control. It therefore seems very important that advisor training addresses this issue and stresses the difference between the two orientations.

Finally, we suggest that what lies behind the three types of support and allows them to be displayed is the extent to which advisors trust their $\mathrm{PhD}$ students. In other words, we suggest that a supervisor who firmly believes that their students have the required competences, that they will follow through to the end and succeed in their $\mathrm{PhD}$, and that they are working conscientiously, will be in good position to offer them support for autonomy, involvement and structure. Conversely, an advisor who does not experience such trust will not be able to offer a supportive attitude to his/her PhD students.

\section{Limitations and Perspectives for Future Research}

A first limitation of the present study is that these results were based solely on interviews with doctoral students. These interviews were self-reported and retrospective stories. They do not reflect an objective reality but the doctoral students' perception of this reality (Vaismoradi et al., 2013). Further, because the interviews focused on participants' past experience, participants may have been liable to rewrite their stories in a way that is meaningful to them and that protects their self-esteem.

A second limitation is that we have no information about the supervisors' perceptions of the situation, about the supervisors' objectives, constraints, pressures and issues at stakes, or about the broader context they are working in (Bøgelund, 2015). This prevents us from cross-checking the information in order to reach a more objective view of the situation, or to get a better understanding of the reasons that lead supervisors to act in one way or another. For example, if the research direction that the $\mathrm{PhD}$ students wishes to pursue is inappropriate and if the student persists in this direction, then the supervisor has no other choice than to be controlling and ask them to change direction. Other advisors might also be reluctant to let students follow a research direction they have less expertise in because they know that this would make them unable to offer students as much structure as they had wished to. This may therefore lead supervisors to be controlling in asking students to remain within their area of expertise. The students are also very different from one another and it is sometimes difficult to know the extent to which a particular style is best suited to a particular student.

Yet, the purpose of the article was not to assess the quality the supervisors' practices or to reach objectivity. The aim of this study was to understand doctoral students' subjective experiences of supervision, to analyze the practices that they reported in the perspective of SDT, and to question and discuss this framework in the light of these findings in order to suggest new developments.

In order to improve our understanding of doctoral supervision, future research could explore these dimensions of the supervisory relationship from different perspectives and using different meth- 
ods, such as interviews of completers and non-completers coupled with interviews of their advisors and observational investigations of the working context. A central aim for future studies would be to address the influence of trust on supporting styles and students' outcomes, both in qualitative studies that explicitly address this question and in quantitative studies that analyze the relationships between these constructs. Further, as mentioned above, it would be relevant that future studies investigate more deeply the possible differences in supervisor support across disciplines, possibly with theoretical frameworks that enables to better identify and investigate these differences (e.g. organizational and/or sociological perspectives that depict cultural specificities) than SDT, which focuses on universal processes across contexts. Quantitative multi-level analyses would also be needed to locate the level in which those differences in supporting styles appear more strongly (e.g. individual, supervisor, team, university or discipline level). Finally, an aspect of supervisory relationships that has not been taken into consideration here and which would be worth exploring is how they evolve in time. Supervising styles are likely to vary greatly across the length of candidature (e.g. offering more structure in the beginning and more autonomy in the end) and there is a need for studies investigating these changes and their effect on doctoral students' motivational outcomes.

\section{References}

Appleton, J. J., Christenson, S. L., \& Furlong, M. J. (2008). Student engagement with school: Critical conceptual and methodological issues of the construct. Psychology in the Schools, 45, 369-386.

Barnes, B. J., \& Austin, A. E. (2009). The role of doctoral advisors: A look at advising from the advisor's perspective. Innovative Higher Education, 33, 297-315.

Barnes, B. J., Williams, E. A., \& Archer, S. A. (2010). Characteristics that matter most: Doctoral students' perceptions of positive and negative advisor attributes. NACADA Journal, 30(1), 34-46.

Bell-Ellison, B., \& Dedrick, R. (2008). What do doctoral students value in their ideal mentor? Research in Higher Education, 49(6), 555-567.

Berk, R. A., Berg, J., Mortimer, R., Walton-Moss, B., \& Yeo, T. (2005) Measuring the effectiveness of faculty mentoring relationships. Academic Medicine, 80(1), 66-71.

Bertaux, D. (1981). From the life-history approach to the transformation of sociological practice. In D. Bertaux (Ed.), Biography and society: The life history approach in the social sciences (pp.29-45). London: Sage.

Blanchet, A., \& Gotman, A. (2010). L'entretien: L'enquête et ses méthodes [The interview: Methods for investigating] (2nd ed.). Paris: Armand Colin.

Bøgelund, P. (2015). How supervisors perceive PhD supervision - And how they practice it. International Journal of Doctoral Studies, 10, 39-55. Retrieved from http://ijds.org/Volume10/IJDSv10p039055Bogelund0714.pdf

Boyatzis, R. E. (1998). Transforming qualitative information: Thematic analysis and code development. Thousand Oaks, CA: Sage.

Braun, V., \& Clarke, V. (2006). Using thematic analysis in psychology. Qualitative Research in Psychology, 3, 77-101.

Brower, H. H., Lester, S., Korsgaard, M. A., \& Dineen, B. (2009). A closer look at trust between managers and subordinates: Understanding the effects of both trusting and being trusted on subordinate outcomes. Journal of Management, 35, 327-347.

Colquitt, J. A., Scott, B. A., \& LePine, J. A. (2007). Trust, trustworthiness, and trust propensity: A metaanalytic test of their unique relationships with risk taking and job performance. Journal of Applied Psychology, 92(4), 909-927. 
Deci, E. L., \& Ryan, R. M. (2000). The 'what' and 'why' of goal pursuits: Human needs and the selfdetermination of behavior. Psychological Inquiry, 11(4), 227-268.

Deuchar, R. (2008). Facilitator, director or critical friend? Contradiction and congruence in doctoral supervision styles. Teaching in Higher Education, 13(4), 489-500.

Edwards, J. R. (2008). Person-environment fit in organizations: An assessment of theoretical progress. The Academy of Management Annals, 2, 167-230.

Fereday, J., \& Muir-Cochrane, E. (2006). Demonstrating rigor using thematic analysis: A hybrid approach of inductive and deductive coding and theme development. International Journal of Qualitative Methods, 5(1), 80-92.

Franke, A., \& Arvidsson, B. (2011). Research supervisors' different ways of experiencing supervision of doctoral students. Studies in Higher Education, 36(1), 7-19.

Gardner, S. K. (2007). "I heard it through the grapevine": Doctoral student socialization in chemistry and history. Higher Education, 54, 723-740.

Gardner, S. K. (2010). Contrasting the socialization experiences of doctoral students in high- and lowcompleting departments: A qualitative analysis of disciplinary contexts at one institution. The Journal of Higher Education, 81(1), 61-81.

Gatfield, T. (2005). An investigation into PhD supervisory management styles: Development of a dynamic conceptual model and its managerial implications. Journal of Higher Education Policy \& Management, 27(3), 311-325.

Gilgun, J. F. (2005). Qualitative research and family psychology. Journal of Family Psychology, 19(1), 4050.

Gillet, N., Gagné, M., Sauvagère, S., \& Fouquereau, E. (2013). The role of supervisor autonomy support, organizational support, and autonomous and controlled motivation in predicting employees' satisfaction and turnover intentions. European Journal of Work and Organizational Psychology, 22(4), 450460 .

Golde, C. M. (2005). The role of the department and discipline in doctoral student attrition: Lessons from four departments. The Journal of Higher Education, 76(6), 669-700.

Grant, K., Hackney, R., \& Edgar, D. (2014). Postgraduate research supervision: An 'agreed' conceptual view of good practice through derived metaphors. International Journal of Doctoral Studies, 9, 43-60. Retrieved from http://ijds.org/Volume9/IJDSv9p043-060Grant0403.pdf

Gurr, G. (2001). Negotiating the "rackety bridge" - A dynamic model for aligning supervisory style with research student development. Higher Education Research and Development, 20, 81-92.

Goddard, R. D., Tschannen-Moran, M., \& Hoy, W. K. (2001). A multilevel examination of the distribution and effects of teacher trust in students and parents in urban elementary schools. The Elementary School Journal, 1, 3-17.

Guest, G., Bunce, A., \& Johnson, L. (2006). How many interviews are enough? An experiment with data saturation and variability. Field Methods, 18(1), 59-82.

Hollingsworth, M. A., \& Fassinger, R. E. (2002). The role of faculty mentors in the research training of counseling psychology doctoral students. Journal of Counseling Psychology, 49, 324-330.

Hsieh, H.-F., \& Shannon, S. E. (2005). Three approaches to qualitative content analysis. Qualitative Health Research, 15(9), 1277-1288.

Jairam, D., \& Kahl Jr., D. H. (2012). Navigating the doctoral experience: The role of social support in successful degree completion. International Journal of Doctoral Studies, 7, 311-329. Retrieved from http://ijds.org/Volume7/IJDSv7p311-329Jairam0369.pdf 
Jang, H., Reeve, J., \& Deci, E. L. (2010). Engaging students in learning activities: It is not autonomy support or structure, but autonomy support and structure. Journal of Educational Psychology, 102, 588600 .

Jones, M. (2013). Issues in doctoral studies - Forty years of journal discussion: Where have we been and where are we going? International Journal of Doctoral Studies, 8, 83-104. Retrieved from http://ijds.org/Volume8/IJDSv8p083-104JonesFT129.pdf

Kristof-Brown, A. L., Zimmerman, R. D., \& Johnson, E. C. (2005). Consequences of individuals' fit at work: A meta-analysis of person-job, person-organization, person-group, and person-supervisor fit. Personnel Psychology, 58, 281-342.

Kuzel, A. J. (1992). Sampling in qualitative inquiry. In B. F. Crabtree \& W. L. Miller (Eds.). Doing qualitative research. Research Methods for Primary Care (pp. 31-44). Newbury Park, CA: Sage.

Leclerc-Olive, M. (1997). Le dire de l'évènement (biographique) [Telling (biographical) events]. Villeneuve d'Ascq: Presses Universitaires du Septentrion.

Lee, A. (2008). How are doctoral students supervised? Concepts of doctoral research supervision. Studies in Higher Education, 33(3), 267-281.

Litalien, D. (2014). Persévérance aux études de doctorat (Ph.D.): modèle prédictif des intentions d'N-C [Persisting in the $\mathrm{PhD}$ : A model predicting intention to quit] (Doctoral dissertation). Université Laval, Québec, Canada. Retrieved March 25, 2015 from http://www.theses.ulaval.ca/2014/30573/30573.pdf

Mainhard, T., van der Rijst, R., Tartwijk, J.-V., \& Wubbels, T. (2009). A model for the supervisor-doctoral student relationship. Higher Education, 58(3), 359-373.

Martinsuo, M., \& Turkulainen, V. (2011). Personal commitment, support and progress in doctoral studies. Studies in Higher Education, 36(1), 103-120.

Mason, M. (2010). Sample size and saturation in PhD using qualitative interviews. Forum Qualitative Social Research, 11(3), 1-13.

Mayer, R. C., Davis, J. H., \& Schoorman, F. D. (1995). An integrative model of organizational trust. Academy of Management Review, 20, 709 -734.

McAlpine, L., \& McKinnon, M. (2013). Supervision - the most variable of variables: Student perspectives. Studies in Continuing Education, 35(3), 265-280.

McAlpine, L., \& Mitra, M. (2015). Becoming a scientist: PhD workplaces and other sites of learning. International Journal of Doctoral Studies, 10, 111-128. Retrieved from http://ijds.org/Volume10/IJDSv10p111-128McAlpine0768.pdf

McLellan, E., MacQueen, K. M., \& Neidig, J. L. (2003). Beyond the qualitative interview: Data preparation and transcription. Field Methods, 15(1), 63-84.

Meijer, P. C., de Graaf, B., \& Meirink, J.A. (2011). Key experiences in student teachers' development. Teachers and Teaching: Theory and Practice, 17, 115-129.

Meirieu, P. (2008). Le pari d'éducabilité [The assumption of teachability]. Retrieved from http://www.meirieu.com/ARTICLES/educabilite.pdf

Miles, M., \& Huberman, A. M. (1994). Qualitative data analysis. Thousand Oaks, CA: Sage Publications.

Oliver, D., Serovich, J. M., \& Mason, T. L. (2005). Constraints and opportunities with interview transcription: Towards reflective practice in HIV/AIDS intervention research. Social Forces, 84(2), 1273-1289.

Paglis, L. L., Green, S. G., \& Bauer, T. N. (2006). Does adviser mentoring add value? A longitudinal study of mentoring and doctoral student outcomes. Research in Higher Education, 47(4), 451-476.

Pole, C. J., \& Sprokkereef, A. (1997). Supervision of doctoral students in the natural sciences: Expectations and experiences. Assessment \& Evaluation in Higher Education, 22(1), 49-63. 
Pyhältö, K., Vekkaila, J., \& Keskinen, J. (2012). Exploring the fit between doctoral students' and supervisors' perceptions of resources and challenges vis-à-vis the doctoral journey. International Journal of Doctoral Studies, 7, 395-414. Retrieved from http://ijds.org/Volume7/IJDSv7p395-414Pyhalto383.pdf

Reeve, J. (2009). Why teachers adopt a controlling motivating style toward students and how they can become more autonomy supportive. Educational Psychologist, 44, 159-178.

Rose, G. L. (2003). Enhancement of mentor selection using the Ideal Mentor Scale. Research in Higher Education, 44, 473-494.

Schilling, J. (2006). On the pragmatics of qualitative assessment: Designing the process for content analysis. European Journal of Psychological Assessment, 22(1), 28-37.

Schlosser, L. Z., \& Kahn, J. H. (2007). Dyadic perspectives on advisor-advisee relationships in counseling psychology doctoral programs. Journal of Counseling Psychology, 54(2), 211-217.

Skinner, E. A., \& Belmont, M. J. (1993). Motivation in the classroom: Reciprocal effects of teacher behavior and student engagement across the school year. Journal of Educational Psychology, 85, 571-581.

Stroet, K., Opdenakker, M.-C., \& Minnaert, A. (2013). Effects of need supportive teaching on early adolescents' motivation: A review of the literature. Educational Research Review, 9, 65-87.

Vaismoradi, M., Turunen, H., \& Bondas, T. (2013). Content analysis and thematic analysis: Implications for conducting a qualitative descriptive study. Nursing \& Health Sciences, 15(3), 398-405.

Van Maele, D., \& Van Houtte, M. (2011). The quality of school life: Teacher-student trust relationships and the organizational school context. Social Indicators Research, 100(1), 85- 100.

Vansteenkiste, M., Niemiec, C. P., \& Soenens, B. (2010). The development of the five mini-theories of self-determination theory: An historical overview, emerging trends, and future directions. In T. C. Urdan \& S. A. Karabenick (Eds.), Advances in motivation and achievement. The decade ahead: Theoretical perspectives on motivation and achievement (pp. 105-165). London: Emerald Group Publishing.

Vekkaila, J., Pyhältö, K., \& Lonka, K. (2013). Experiences of disengagement - A study of doctoral students in the behavioral sciences. International Journal of Doctoral Studies, 8, 61-81. Retrieved from http://ijds.org/Volume8/IJDSv8p061-081Vekkaila0402.pdf

Vilkinas, T. (2008). An exploratory study of the supervision of $\mathrm{PhD} /$ research students' theses. Innovative Higher Education, 32, 297-311.

Wao, H. O., \& Onwuegbuzie, A. J. (2011). A mixed research investigation of factors related to time to the doctorate in education. International Journal of Doctoral Studies, 6, 115-134. Retrieved from http://ijds.org/Volume6/IJDSv6p115-134Wao320.pdf

Watson, M. S., \& Ecken, L. (2003). Learning to trust: Transforming difficult elementary classrooms through developmental discipline. San Francisco: Jossey-Bass.

Weber, R. P. (1990). Basic content analysis. Newbury Park, CA: Sage Publications.

Weibel, A., \& Six, F. E. (2013). Trust and control: the role of intrinsic motivation. In R. Bachmann and A. Zaheer (Eds.), Handbook of advances in trust research (pp. 57-81). Cheltenham: Edward Elgar.

Zhang, Y., \& Wildemuth, B. M. (2009). Qualitative analysis of content. In B. Wildemuth (Ed.), Applications of social research methods to questions in information and library science (pp.308-319). Westport, CT: Libraries Unlimited.

Zhao, C. M., Golde, C. M., \& McCormick, A. C. (2007). More than a signature: How advisor choice and advisor behaviour affect doctoral student satisfaction. Journal of Further and Higher Education, 31(3), 263-281. 


\section{Biographies}

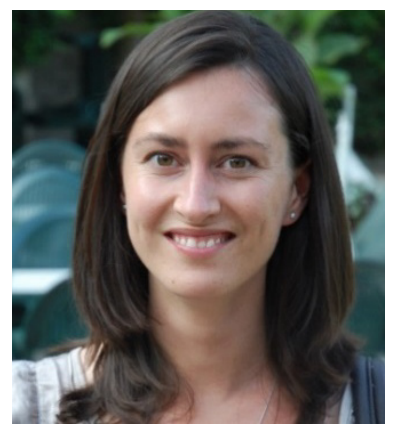

Christelle Devos, $\mathrm{PhD}$, is a post-doctoral researcher in educational psychology at the Université catholique de Louvain, Belgium. Her research interests include doctoral engagement and persistence, training transfer and beginning teachers' experiences. More information about her can be found on http://www.researchgate.net/profile/Christelle_Devos. She can be reached at: christelle.devos@uclouvain.be

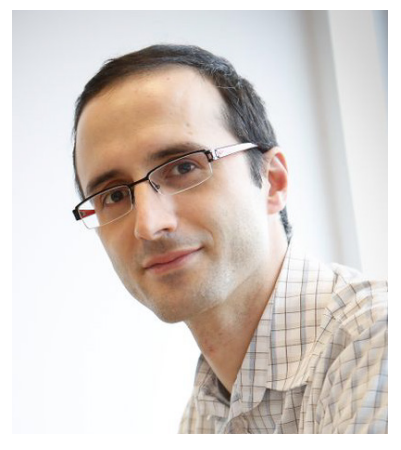

Nicolas Van der Linden, $\mathrm{PhD}$, is a post-doctoral researcher in social psychology at the Université Libre de Bruxelles, Belgium. His research interests include doctoral engagement and persistence, diary-based learning, social stereotypes, and intergroup conflicts. More information about him can be found on http://www.psychopsysoc.site.ulb.ac.be/equipe/nicolas-van-der-linden. He can be reached at nivdlind@ulb.ac.be

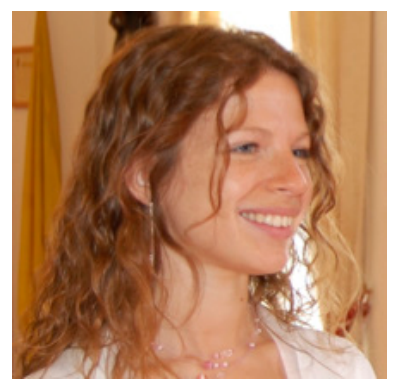

Gentiane Boudrenghien, $\mathrm{PhD}$, is a post-doctoral researcher in educational psychology at the Université catholique de Louvain, Belgium. Her research interests include doctoral engagement, educational and professional transitions, and persistence in academic or professional goals. She can be reached at gentiane.boudrenghien@uclouvain.be

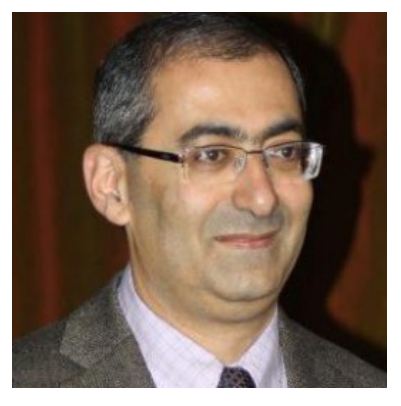

Assaad Azzi, PhD, is a Professor and Head of the Social Psychology unit at the Université Libre de Bruxelles, Belgium. His research interests include intergroup relations, acculturation, discrimination, and perception of justice. More information about him can be found on http://www.psycho-psysoc.site.ulb.ac.be/equipe/assaad-azzi. He can be reached at: aazzi@ulb.ac.be

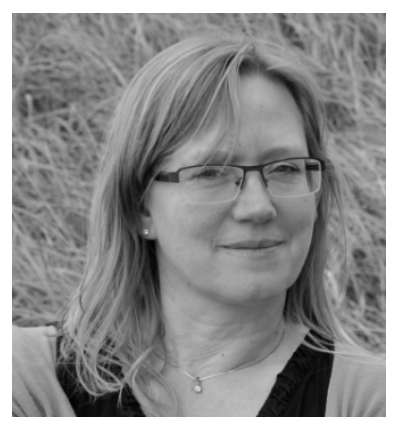

Mariane Frenay, $\mathrm{PhD}$, is a Professor at the Université catholique de Louvain, Belgium. Her research interests include students' persistence and academic achievement, learning and professional development in higher education. More information about her can be found on http://www.uclouvain.be/mariane.frenay. She can be reached at: mariane.frenay@uclouvain.be 


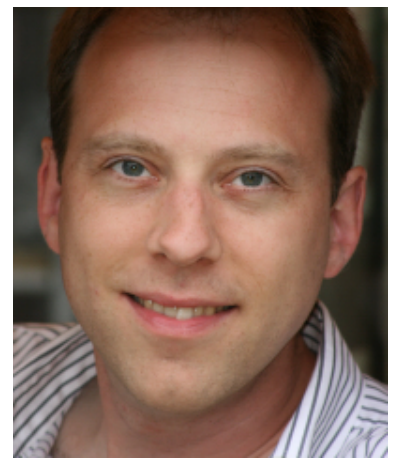

Benoît Galand, PhD, is a Professor at the Université catholique de Louvain, Belgium. His research interests include motivation and engagement in learning, violence and bullying in schools, and teachers' professional practices. More information about him can be found on http://www.uclouvain.be/benoit.galand. He can be reached at: benoit.galand@uclouvain.be

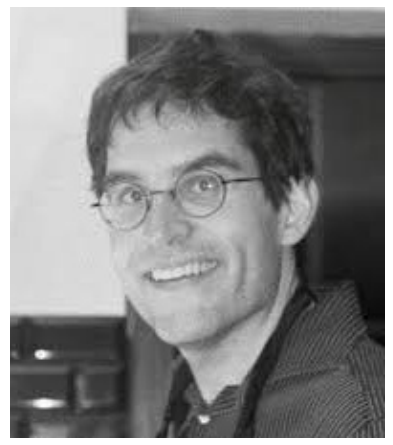

Olivier Klein, $\mathrm{PhD}$, is a Professor and head of the Center for Social and Cultural Psychology at the Université Libre de Bruxelles, Belgium. His research interests concern social stereotypes, objectivation and dehumanization, and social influences on memory. He also is chief editor (with Céline Darnon) of the International Review of Social Psychology. More information about him can be found on http://www.psycho-psysoc.site.ulb.ac.be/equipe/olivier-klein. He can be reached at: oklein@ulb.ac.be 